\title{
Increased cloud activation potential of secondary organic aerosol for atmospheric mass loadings
}

\author{
S. M. King ${ }^{1, *}$, T. Rosenoern ${ }^{1, *}$, J. E. Shilling ${ }^{1, * *}$, Q. Chen ${ }^{1}$, and S. T. Martin ${ }^{1,2}$ \\ ${ }^{1}$ School of Engineering and Applied Sciences, Harvard University, Cambridge, MA 02138, USA \\ ${ }^{2}$ Department of Earth and Planetary Sciences, Harvard University, Cambridge, MA 02138, USA \\ * now at: Institut de Recherches sur la Catalyse et l'Environnement de Lyon, UMR5256, Université de Lyon 1, \\ CNRS, Villeurbanne, France \\ ** now at: Pacific Northwest National Laboratory, Atmospheric Sciences and Global Change Division, \\ Richland, WA 99352, USA
}

Received: 17 November 2008 - Published in Atmos. Chem. Phys. Discuss.: 12 January 2009

Revised: 20 April 2009 - Accepted: 27 April 2009 - Published: 6 May 2009

\begin{abstract}
The effect of organic particle mass loading from 1 to $\geq 100 \mu \mathrm{g} \mathrm{m}^{-3}$ on the cloud condensation nuclei $(\mathrm{CCN})$ properties of mixed organic-sulfate particles was investigated in the Harvard Environmental Chamber. Mixed particles were produced by the condensation of organic molecules onto ammonium sulfate particles during the dark ozonolysis of $\alpha$-pinene. A continuous-flow mode of the chamber provided stable conditions over long time periods, allowing for signal integration and hence increased measurement precision at low organic mass loadings representative of atmospheric conditions. CCN activity was measured at eight mass loadings for 80- and 100-nm particles grown on 50nm sulfate seeds. A two-component (organic/sulfate) Köhler model, which included the particle heterogeneity arising from DMA size selection and from organic volume fraction for the selected 80- and 100-nm particles, was used to predict $\mathrm{CCN}$ activity. For organic mass loadings of $2.9 \mu \mathrm{g} \mathrm{m}^{-3}$ and greater, the observed activation curves were well predicted using a single set of physicochemical parameters for the organic component. For mass loadings of $1.74 \mu \mathrm{g} \mathrm{m}^{-3}$ and less, the observed $\mathrm{CCN}$ activity increased beyond predicted values using the same parameters, implying changed physicochemical properties of the organic component. A sensitivity analysis suggests that a drop in surface tension must be invoked to explain quantitatively the $\mathrm{CCN}$ observations at low SOA particle mass loadings. Other factors, such as decreased
\end{abstract}

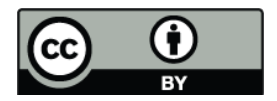

Correspondence to: S. T. Martin (scot_martin@harvard.edu) molecular weight, increased density, or increased van't Hoff factor, can contribute to the explanation but are quantitatively insufficient as the full explanation.

\section{Introduction}

Quantifying the potential of atmospheric particles to form cloud droplets is necessary for estimating the radiative forcing due to aerosol indirect effects, which at present have large uncertainties (IPCC, 2007). Recent models of these effects incorporate predictions of particle activation based on Köhler models (Lohmann and Feichter, 2005). Past laboratory investigations have shown that simple Köhler models agree well with measured cloud condensation nuclei (CCN) activity of inorganic particles (McFiggans et al., 2006). Atmospheric particles, however, also contain a significant mass fraction of complex organic compounds, and several laboratory studies using environmental chambers have been recently conducted to describe the CCN activation of secondary-organic-aerosol (SOA) particles produced by the oxidation of monoterpenes and sesquiterpenes (Hartz et al., 2005; VanReken et al., 2005; King et al., 2007; Prenni et al., 2007; Duplissy et al., 2008; Engelhart et al., 2008). Environmental chambers provide controlled surrogate atmospheres in which the formation of SOA can occur through the oxidation reactions of primary gaseous precursors. The results in these experiments suggest that the organic fraction of atmospheric particles could be more $\mathrm{CCN}$ active than previously thought. 


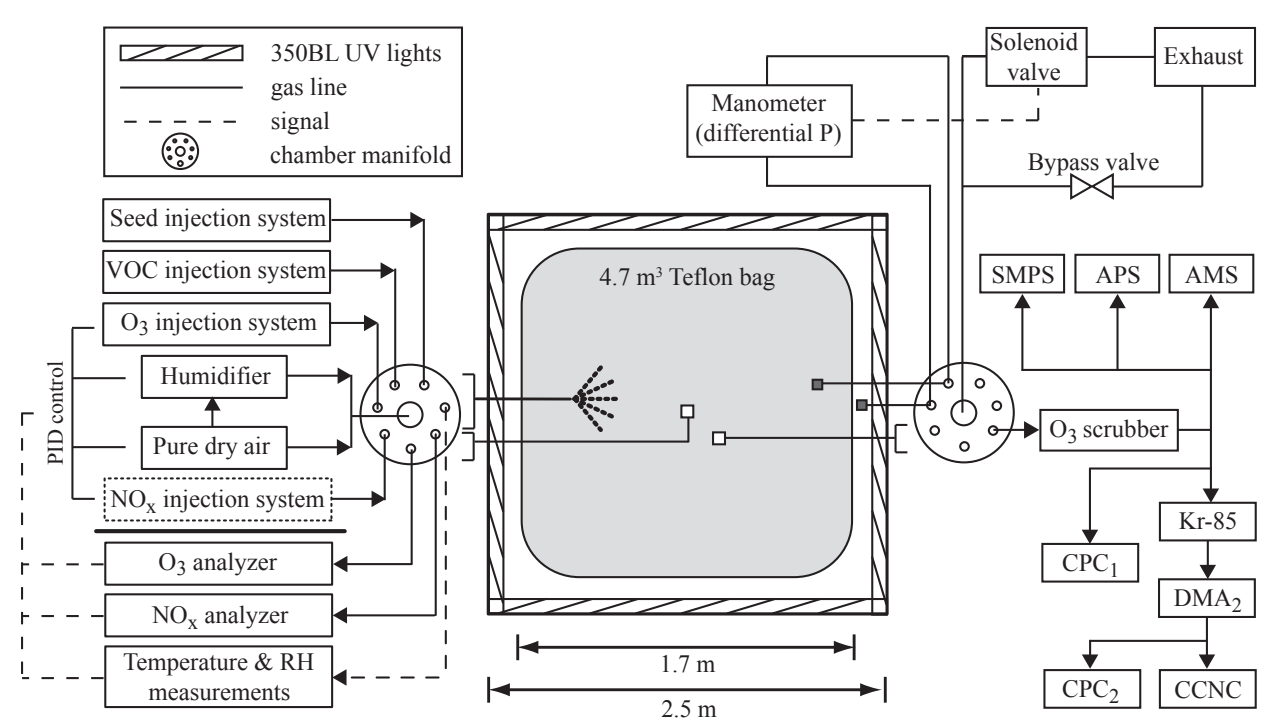

Fig. 1. Schematic diagram of the Harvard Environmental Chamber. There are injection systems for size-selected seed particles, VOC precursor, $\mathrm{O}_{3}$, humidity, and $\mathrm{NO}_{\mathrm{x}}$. There are sampling and measurement systems for $\mathrm{O}_{3}, \mathrm{NO}_{\mathrm{x}}$, temperature, relative humidity, particle size distribution (SMPS \& APS), particle number concentration (CPC), particle chemistry (HR-ToF-AMS), and size-resolved CCNC activity (CPC \& CCNC). Table 1 summarizes the instrumentation. Feedback controls maintain $\mathrm{O}_{3}$, temperature, and relative humidity at fixed values. A differential pressure system balances outflow and inflow.

The CCN activity of particles containing organic compounds may be enhanced by a reduction in surface tension from that of purely inorganic particles (Facchini et al., 1999; Svenningsson et al., 2006; Engelhart et al., 2008). King et al. (2007) reported on the CCN activity of internally mixed particles of ammonium sulfate and $\alpha$-pinene SOA organic material and found that the critical supersaturations were well predicted using a two-component Köhler model, specifically one component as ammonium sulfate and a second component representing the effective properties of the organic material. Agreement between the observations and the predictions of the Köhler model led to the conclusion that a surface tension of water was consistent with the observed activation of the mixed organic-sulfate particles. This finding was in agreement with several previous studies (Hegg et al., 2001; Ervens et al., 2005; Hartz et al., 2005) but in apparent disagreement with an assumption of a reduction in surface tension by particle-phase organic molecules (Facchini et al., 1999; Svenningsson et al., 2006; Engelhart et al., 2008).

The aforementioned studies of SOA CCN activity were performed in environmental chambers using biogenic volatile-organic-compound (VOC) precursor concentrations significantly greater than those commonly occurring in the atmosphere (Hartz et al., 2005; VanReken et al., 2005; King et al., 2007; Prenni et al., 2007; Duplissy et al., 2008; Engelhart et al., 2008). For example, the lowest injected $\alpha$-pinene concentrations for batch and continuous-flow chambers were $10 \mathrm{ppbv}$ in Duplissy et al. (2008) and $24 \mathrm{ppbv}$ in King et al. (2007), respectively. Given the dependency of the particlephase composition of SOA on organic mass loading (Sein- feld and Pankow, 2003; Donahue et al., 2006; Shilling et al., 2009), the CCN activity may also change. Although observations of CCN activity at high SOA particle mass loadings suggested an absence of any effect of organic molecules on surface tension, the hypothesis motivating our present study was that such effects may nevertheless emerge with the changed particle composition at low mass loadings representative of atmospheric concentrations. To explore this possibility, we undertook the studies described in this paper on the $\mathrm{CCN}$ activity of mixed organic-sulfate particles for variable mass loading. The CCN activity was investigated for organic particle mass loadings from 0.95 to $\geq 95.2 \mu \mathrm{g} \mathrm{m}^{-3}$, a range across which considerable changes in the organic chemical composition can be expected based upon partitioning theory (Donahue et al., 2006; Shilling et al., 2009).

\section{Experimental}

\subsection{Overview}

Inside the Harvard Environmental Chamber (HEC) (Fig. 1), organic molecules produced by the dark ozonolysis of $\alpha$ pinene partition among the gas phase, the particle phase, and the walls. Initial condensation to the particle phase occurs on the surfaces of ammonium sulfate seed particles. Two types of environmental chambers have been described in previous reports, batch-mode chambers (Cocker et al., 2001b; Paulsen et al., 2005; Stanier et al., 2007) and continuous-flow chambers (Kleindienst et al., 1999). Continuous-flow operation is used for this study because conditions can be held stable over 
long time periods, allowing for more precise measurements through signal integration for low organic mass loadings representative of atmospheric conditions. For example, data in this study are collected over extended time periods ( 4 to $12 \mathrm{~h}$ ) at organic loadings as low as $0.95 \mu \mathrm{g} \mathrm{m}^{-3}$.

In a typical experiment, ammonium sulfate seed particles having an electric mobility equivalent to $50-\mathrm{nm}$ spherical particles of +1 charge are selected using $\mathrm{DMA}_{1}$ (Fig. 2). The transmitted aerosol includes both a mode of singly charged $(+1)$ particles centered around a geometric diameter of $50 \mathrm{~nm}$ and a second mode of doubly charged $(+2)$ particles centered around a geometric diameter of $73 \mathrm{~nm}$. Organic molecules produced by the dark ozonolysis of $\alpha$-pinene deposit onto these seed particles, leading to condensational growth. The rate of growth depends on the $\alpha$-pinene concentration. The size distributions of the particles exiting the chamber are polydisperse, both because of several geometric modes of seed particles and because of the variability of particle residence times (i.e., growth times) in a continuously stirred tank reactor. From the particles exiting the chamber, 80- and 100-nm electric-mobility-equivalent particles are selected by $\mathrm{DMA}_{2}$ for $\mathrm{CCN}$ analysis (Fig. 1). These particles contain a range of organic volume fractions, such as low fractions resulting from large $(73 \mathrm{~nm})$ seed particles that have short residence times and high fractions resulting from small $(50 \mathrm{~nm})$ seed particles that have long residence times. Additional heterogeneity arises from the transmission of multiply charged particles through $\mathrm{DMA}_{2}$ (e.g., 80- and 120 -nm geometric diameter for a setting of $80-\mathrm{nm}$ mobility diameter on $\mathrm{DMA}_{2}$ ). Interpretation of the $\mathrm{CCN}$ observations must account for these heterogeneities at a selected mobility diameter.

\subsection{Chamber}

A schematic diagram of the environmental chamber, including the associated injection systems and analysis instrumentation, is shown in Fig. 1. The constant-temperature chamber $\left(2.5 \times 2.5 \times 2.75 \mathrm{~m}^{3}\right.$; Luwa Environmental Specialties) houses a flexible $4.7-\mathrm{m}^{3} \mathrm{bag}\left(1.7 \times 1.7 \times 1.7 \mathrm{~m}^{3}\right)$, which is made from $0.05 \mathrm{~mm}$ (2 mil) PFA Teflon (Welch Fluorocarbon). The bag is suspended by a frame of stainless steel tubes, which also supports the bottom of the bag. The floor, the ceiling, and the walls of the chamber are covered by reflective aluminum sheets to maximize reflected light intensity. For wavelengths longer than $300 \mathrm{~nm}$, the aluminum sheets have reflectivity better than $80 \%$. Ultraviolet irradiation is provided by forty-six 40-W Sylvania 350BL blacklights affixed to the walls. Except for bag cleaning, the blacklights are not used in this study.

The chamber is operated in a feedback-controlled continuous-flow mode (Kleindienst et al., 1999). Total flow, relative humidity, temperature, $\mathrm{O}_{3}$ concentration, and $\mathrm{NO}_{\mathrm{x}}$ concentration are monitored and controlled by a PID circuit implemented in Labview. The inlet flow is balanced with
Table 1. Instrumentation outfitted for use with the environmental chamber.

\begin{tabular}{ll}
\hline Instrument & Measured parameter \\
\hline Teledyne 400E ozone analyzer & $\mathrm{O}_{3}$ \\
Teledyne 200E NOx analyzer & $\mathrm{NO}, \mathrm{NO}_{2}$ \\
Rotronic Hygroclip SC05 sensor & $\begin{array}{l}\text { relative humidity and temperature } \\
\text { temperature }\end{array}$ \\
$\begin{array}{l}\text { Thermocouple type K } \\
\text { Ocean Optics USB2000 UV/VIS }\end{array}$ & light spectrum \\
spectrometer & total particle number concentration \\
TSI 3025 condensation particle & \\
counter (CPC) & number-weighted particle size \\
Scanning mobility particle sizer & distribution $(0.01-1 \mu$ m) \\
(TSI 3081 DMA and 3772 CPC) & number-weighted particle size \\
TSI 3321 Aerodynamic Particle Sizer (APS) & distribution $(0.5-20 \mu \mathrm{m})$ \\
$\begin{array}{l}\text { Aerodyne high-resolution time-of-flight } \\
\text { aerosol mass spectrometer (HR-ToF-AMS) }\end{array}$ & $\begin{array}{l}\text { aerodynamic diameter and particle } \\
\text { composition }\end{array}$ \\
$\begin{array}{l}\text { Droplet Measurement Technologies cloud } \\
\text { condensation nuclei counter }(\mathrm{CCNC})\end{array}$ & particle CCN properties \\
\hline
\end{tabular}

the outlet flow by maintaining a constant overpressure in the bag of 30 mTorr using PID feedback to control a solenoid valve (Asco 8214). The pressure differential is measured by a manometer (Omega PX277). The temperature of the chamber is maintained within $\pm 1^{\circ} \mathrm{C}$ between 15 and $40^{\circ} \mathrm{C}$ using an internal conditioning plenum that distributes the air evenly through a perforated stainless steel ceiling. An RTD sensor measures the temperature outside of the bag, providing the feedback signal for temperature control.

Instrumentation for gas-phase measurements is summarized in Table 1. Relative humidity is monitored within the bag using a Rotronic Hygroclip SC05 sensor. Ozone levels are measured using a UV absorption ozone analyzer (Teledyne $400 \mathrm{E}$ ). $\mathrm{NO}$ and $\mathrm{NO}_{2}$ concentrations are measured using a chemiluminescent $\mathrm{NO}_{\mathrm{x}}$ analyzer (Teledyne 200E), which is calibrated using a 5 ppmv cylinder of NO (Airgas) diluted in $\mathrm{N}_{2}$. No $\mathrm{NO}_{\mathrm{x}}$ is introduced into the chamber for the dark ozonolysis experiments that constitute this study, and the measured levels remain below the detection limit of $1 \mathrm{ppbv}$. Overall, the continuous-flow mode with feedback controls on total flow, relative humidity, temperature, $\mathrm{O}_{3}$ concentration, and $\mathrm{NO}_{\mathrm{x}}$ concentration maintains an approximately constant composition of gas- and particle-phase compounds during the course of an experiment.

The bag is periodically cleaned by turning off most flows and providing a continuous flow of particle- and hydrocarbon-free air $\left(40 \mathrm{~L} \mathrm{~min}^{-1}\right)$ having $600 \mathrm{ppbv} \mathrm{O}_{3}$ while irradiating with $\mathrm{UV}$ lights at $40^{\circ} \mathrm{C}$ until the particle concentration is less than $1 \mathrm{~cm}^{-3}$ (typically $1-3$ days).

\subsection{Injection systems}

The injection systems, consisting of solenoid valves and mass flow controllers regulated by Labview, are depicted in Fig. 2. An Aadco 737-14A Pure Air Generator removes hydrocarbons, $\mathrm{H}_{2} \mathrm{O}$, and $\mathrm{NO}_{\mathrm{x}}$ from the house compressed air 


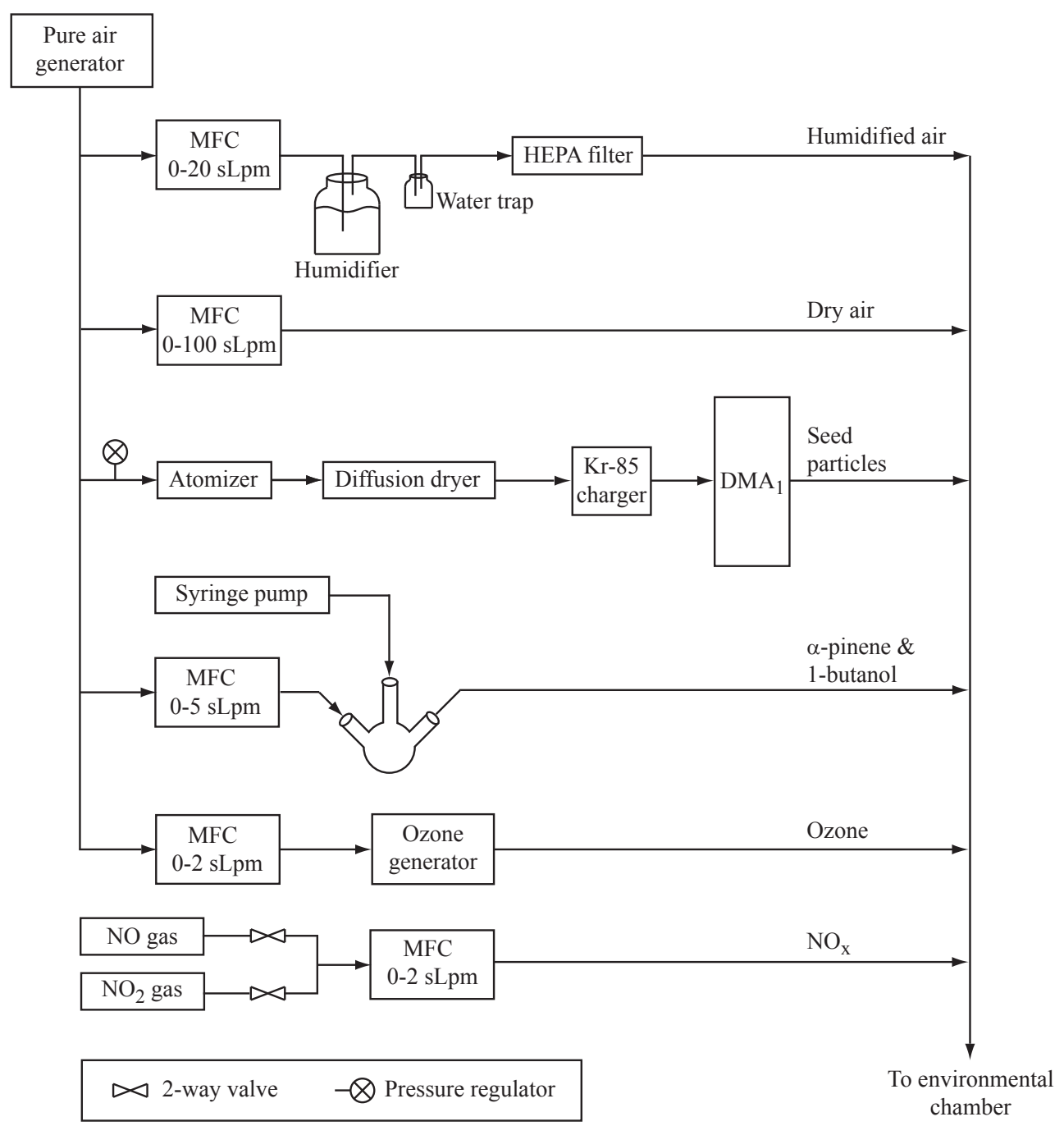

Fig. 2. Diagram of the injection systems for humidified air, dry air, size-selected seed particles, $\alpha$-pinene as the precursor VOC (with 1 butanol as the $\mathrm{OH}$ scavenger), $\mathrm{O}_{3}$, and $\mathrm{NO}_{\mathrm{x}}$. Mass flow controllers (MFC) are used to regulate flow in the injection systems, except in the case of the atomizer used for the seed particles.

to provide a clean dry flow having ambient concentrations of $\mathrm{CO}_{2}$ and $\mathrm{O}_{2}$ and a relative humidity of less than $1 \%$. This air is used for several other subsystems, as indicated in Fig. 2. Ozone is synthesized by passing clean air around an ultraviolet lamp (Jelight 600). Two manifolds, located on opposite sides of the bag, provide multiple ports for injection and sampling lines. With the exception of Teflon lines used to sample $\mathrm{O}_{3}$ and $\mathrm{NO}_{\mathrm{x}}$, the injection and sampling lines are made from stainless steel.

A humid flow for adjusting relative humidity inside the bag is provided by proportional mixing of a near-saturation air flow with a dry-air flow. The near-saturation flow is obtained by bubbling dry air at a variable flow rate through $18 \mathrm{M} \Omega-\mathrm{cm}$ water in a glass container. A HEPA filter (Pall 12144 ) is downstream of the bubbler to remove any particles.
Dry seed particles are continuously generated from $\left(\mathrm{NH}_{4}\right)_{2} \mathrm{SO}_{4}$ solutions $\left(0.1 \mathrm{~g} \mathrm{~L}^{-1}\right)$ using a TSI 3076 atomizer, which is followed by a $160-\mathrm{cm}$ silica gel diffusion dryer that has an exit relative humidity of less than $10 \%$. The polydisperse particles are passed through a ${ }^{85} \mathrm{Kr}$ bipolar charger followed by a differential mobility analyzer $\left(\mathrm{DMA}_{1}\right.$, TSI 3071). For these experiments, $\mathrm{DMA}_{1}$ is set to an electric mobility equivalent to $50-\mathrm{nm}$ spherical particles of +1 charge and operated at a sheath-to-monodisperse flow ratio of 10:3. The exiting number concentration ranges from 5000 to $8000 \mathrm{~cm}^{-3}$. Geometric diameters, as measured by an SMPS, include both a +1 mode at $50 \mathrm{~nm}$ and a significant +2 mode at $73 \mathrm{~nm}$.

$\alpha$-Pinene vapor is introduced using a syringe pump (New Era Pump Systems NE-1000) that continuously injects a mixture of $\alpha$-pinene and 1-butanol (1:600 v/v, 
1:1040 mole/mole) into a gently warmed glass bulb, which is flushed with clean dry air into the chamber. The pumping rate of the syringe determines the amount of $\alpha$-pinene available for reaction in the bag and thus affects the particlephase organic mass loadings in the chamber. The pumping rate is slow enough that the hydrocarbon vapor is released into the glass bulb through evaporation from sessile drops on the tip of the syringe needle, rather than from released drops. 1-Butanol serves as an $\mathrm{OH}$ scavenger.

The total flow rate through the bag is $21.1 \mathrm{sLpm}$, which includes $16 \mathrm{sLpm}$ from the combined wet and dry clean air flows, $2 \mathrm{sLpm}$ from the $\alpha$-pinene/1-butanol flow, $3 \mathrm{sLpm}$ from the seed flow, and up to $0.1 \mathrm{sLpm}$ from the ozone flow. For $21.1 \mathrm{sLpm}$, the corresponding residence time in the chamber is approximately $3.4 \mathrm{~h}$.

\subsection{Particle characterization}

The flow exiting the chamber first passes through a diffusion tube having an outer annulus filled with ozone destruction catalyst (Carus Chemical, Carulite 200). The flow is then split for simultaneous sampling by the particle instrumentation listed in Table 1 and shown in Fig. 1. A scanning mobility particle sizer (SMPS, TSI 3936) measures the electric-mobility-diameter size distribution. A condensation particle counter $\left(\mathrm{CPC}_{1}\right.$, TSI 3022) measures the total number concentration of the particles. An Aerodyne highresolution time-of-flight aerosol mass spectrometer (HRToF-AMS) measures the organic and sulfate mass loadings (DeCarlo et al., 2006). A differential mobility analyzer $\left(\mathrm{DMA}_{2}\right)$ selects a monodisperse mobility-diameter fraction from the aerosol particles at a sheath-to-monodisperse flow ratio of $10: 1.5$, and this fraction is sampled simultaneously by a second CPC $\left(\mathrm{CPC}_{2}\right.$, TSI 3772) and a Droplet Measurement Technologies cloud condensation nucleus counter (CCNC, DMT CCN-2) (Roberts and Nenes, 2005; Lance et al., 2006). The activated fraction $F_{a}$ is calculated as the number concentration of particles activating and growing to $1 \mu \mathrm{m}$ or larger divided by the total number concentration counted by $\mathrm{CPC}_{2}$. $\mathrm{CPC}_{2}$ (TSI 3772) has a detector efficiency greater than $99 \%$ for particles larger than $30 \mathrm{~nm}$. Calibration of the CCNC is performed with $\left(\mathrm{NH}_{4}\right)_{2} \mathrm{SO}_{4}$ (Shilling et al., 2007). Particle charge is re-equilibrated with a ${ }^{85} \mathrm{Kr}$ bipolar charger before sampling by the SMPS or DMA 2 .

\subsection{Protocols}

In a typical experiment, the flows in the chamber are initiated by adjusting the relative humidity to $40 \%$ and the ozone concentration to 50 or $300 \mathrm{ppbv}$ (cf. Table 2). The flow of sulfate seed particles is then initiated, which is followed by the flow of $\alpha$-pinene mixed with 1-butanol. The $\alpha$-pinene reacts with ozone inside the chamber, and the condensation of product molecules of sufficiently low vapor pressure ensues. These mixed organic-sulfate particles pass in the outlet flow
Table 2. Organic particle mass loadings and the corresponding ozone concentrations for the dark ozonolysis of $\alpha$-pinene. The ozone levels are in both cases in stoichiometric excess, and the difference between the two concentrations was not observed to influence the CCN activity so long as similar mass loadings were compared (Shilling et al., 2008).

\begin{tabular}{ccc}
\hline Measurement date & $\begin{array}{c}\text { Organic mass } \\
\text { loading }\left(\mu \mathrm{g} \mathrm{m}^{-3}\right)\end{array}$ & $\mathrm{O}_{3}$ (ppbv) \\
\hline 10 Jan 2007 & 15.4 & 300 \\
13 Jan 2007 & $\geq 95.2$ & 300 \\
17 Jan 2007 & 2.90 & 300 \\
24 Jan 2007 & 6.97 & 300 \\
6 Feb 2007 & 1.24 & 300 \\
12 Feb 2007 & 0.95 & 300 \\
23 Feb 2007 & 1.74 & 50 \\
27 Feb 2007 & 5.01 & 50 \\
\hline
\end{tabular}

from the chamber into several particle instruments for characterization. In the series of experiments constituting this study, the reaction conditions are held constant while the syringe pumping rate of the $\alpha$-pinene and 1-butanol mixture are varied to adjust the resulting organic mass loading (Table 2). Data at one mass loading are typically collected for $2-4$ days.

\section{Theoretical approach}

\subsection{Köhler model}

A two-component Köhler model assuming full solubility is used for calculating the critical supersaturation $S^{*}$ for a particle of dry geometric diameter $D_{\text {geo,dry }}$. The saturation ratio $s$ relative to a flat surface of liquid water is expressed as:

$s=1+S / 100=$

$n_{w}\left(n_{w}+\frac{\pi D_{\mathrm{geo}, \mathrm{dry}}^{3}}{6} \sum_{k \in\{\mathrm{AS}, \mathrm{ORG}\}} i_{k} \varepsilon_{k} V_{m, k}^{-1}\right)^{-1} \exp \left(\frac{4 \sigma V_{m, w}}{R T D_{a q}}\right)$,

where $S$ is the supersaturation (\%), $n_{w}$ is the number of moles of water, $i_{k}$ is the van't Hoff factor of species $k$ in solution, $\varepsilon_{k}$ is the volume fraction of species $k$ in the dry particle, $V_{m, k}$ is the molar volume of species $k$ in the dry particle, $\sigma$ is the surface tension, subscript $w$ refers to pure water, $R$ is the universal gas constant, $T$ is the solution temperature, and $D_{a q}$ is the aqueous particle diameter. Species $k=$ "AS" refers to the ammonium sulfate seed, and species $k=$ "ORG" refers to the organic component of the particle. The maximum of $S\left(D_{a q} ; D_{\mathrm{geo}, \mathrm{dry}}, \varepsilon_{\mathrm{ORG}}\right)$ for variable $D_{a q}$ corresponds to the critical supersaturation $S^{*}\left(D_{\text {geo,dry }}, \varepsilon_{\mathrm{ORG}}\right)$ that must be exceeded for activation. Equation (1) is derived in the supplementary material. 
Table 3. Physical and chemical parameters appearing in Eq. (1) and used in the calculation of the $\mathrm{CCN}$ activation curves shown in Figs. 7 and 8 (King et al., 2007).

\begin{tabular}{ll}
\hline Parameter & Value \\
\hline Surface tension, $\sigma$ & $0.0725 \mathrm{~N} \mathrm{~m}^{-1}$ \\
Molar volume*, $V_{m}, \mathrm{AS}$ & $74.66 \mathrm{~cm}^{3} \mathrm{~mol}^{-1}$ \\
van't Hoff factor of $\left(\mathrm{NH}_{4}\right)_{2} \mathrm{SO}_{4}, i_{\mathrm{AS}}$ & 2.2 \\
Effective van't Hoff factor, $i_{\mathrm{ORG}}$ & 1 \\
Molar volume, $V_{m, \mathrm{ORG}}$ & $148 \mathrm{~cm}^{3} \mathrm{~mol}^{-1}$ \\
\hline
\end{tabular}

* $V_{m}=M / \rho$ where $M$ is molecular weight and $\rho$ is density.

Table 3 shows the base-case values of the physicochemical parameters used in the evaluation of Eq. (1). King et al. (2007) established in a sensitivity study that the CCN activation of dark ozonolysis $\alpha$-pinene SOA can be explained by a surface tension of water. That study also validated the assumption of full solubility of the SOA particle-phase organic component. CCN analysis, however, cannot individually constrain $i_{k}$ and $V_{m, k}$. For AS, these values are independently known, and the values are given in Table 3 . For the organic component, our analysis assigns a formal value of unity to the van't Hoff factor $i_{\text {ORG }}$. The value of $148 \mathrm{~cm}^{3} \mathrm{~mol}^{-1}$ for $V_{m \text {,ORG }}$ shown in Table 3 follows from (a) a density $\rho_{\text {ORG }}$ of $1.2 \pm 0.1 \mathrm{~g} \mathrm{~cm}^{-3}$ based on comparisons between the vacuumaerodynamic size distribution and the electric-mobility size distribution for the highest mass loading of this study (DeCarlo et al., 2004; Katrib et al., 2005; Kostenidou et al., 2007) and (b) a molecular weight $M_{\mathrm{ORG}}\left(178 \mathrm{~g} \mathrm{~mol}^{-1}\right)$ that King et al. (2007) found as the optimal value to explain the $\mathrm{CCN}$ activity of dark ozonolysis $\alpha$-pinene SOA organic material. The value for molar volume was calculated with $\rho_{\mathrm{ORG}}$ measured at the highest mass loading because $\rho_{\mathrm{ORG}}$ is independent of loading above $15.9 \mu^{-3} \mathrm{~m}^{-3}$ (Shilling et al., 2009). For lower loadings, $\rho_{\mathrm{ORG}}$ increases, and these changes are incorporated in the present study as perturbations at low loadings to the base-case value of $V_{m}$,ORG. For comparison to our base-case value of $148 \mathrm{~cm}^{3} \mathrm{~mol}^{-1}$, Hartz et al. (2005) reported a value of $146 \mathrm{~cm}^{3} \mathrm{~mol}^{-1}$. In the framework of the $\kappa$-Köhler model of Petters and Kreidenweis (2007), the organic parameters of Table 3 correspond to $\kappa_{\mathrm{ORG}}=0.12$ (Rose et al., 2007).

\subsection{Calculated CCN activation curves}

The activation curves correspond to the activated fraction $F_{a}$ for increasing supersaturation $S$ at a setpoint mobility diameter $D_{m}$. The activation curve $F_{a}\left(S ; D_{m}\right)$ is expressed by Eq. (2):

$F_{a}\left(S ; D_{m}\right)=\frac{N_{\mathrm{CCNC}}\left(S ; D_{m}\right)}{N_{\mathrm{CPC}}\left(D_{m}\right)}$ for the number concentration of activated particles $N_{\mathrm{CCNC}}\left(S ; D_{m}\right)$ and the total number concentration $N_{\mathrm{CPC}}\left(D_{m}\right)$.

The quantities $N_{\mathrm{CPC}}\left(D_{m}\right)$ and $N_{\mathrm{CCNC}}\left(S ; D_{m}\right)$ can be calculated for the population of particles exiting the chamber. The population has a two-dimensional size/composition distribution $n_{\text {chamber }}\left(D_{\mathrm{geo}}, \varepsilon_{\mathrm{ORG}}\right)$, where $D_{\mathrm{geo}}$ is the geometric diameter and $\varepsilon_{\mathrm{ORG}}$ is the volume fraction of organic material. The particles have a negligible water content when exiting the chamber and passing $\mathrm{DMA}_{2}$ at $40 \% \mathrm{RH}$ (Cocker et al., 2001a), implying both that $D_{\text {geo }}=D_{\text {geo, dry }}$ and that the organic volume fraction is balanced by ammonium sulfate (i.e., $\varepsilon_{\mathrm{ORG}}+\varepsilon_{\mathrm{AS}}=1$ ). For singly charged spherical particles, the mobility diameter and the geometric diameter are equal (Katrib et al., 2005).

The quantity $N_{\mathrm{CPC}}\left(D_{m}\right)$ of Eq. (2) is calculated for $100 \%$ CPC detection efficiency using the following expression (Alofs and Balakumar, 1982; Collins et al., 2002):

$N_{\mathrm{CPC}}\left(D_{m}\right)=$

$\int_{0}^{\infty} \sum_{j=-\infty}^{+\infty} \Omega\left(D_{\mathrm{geo}}, j ; D_{m}\right) \varphi\left(D_{\mathrm{geo}}, j\right) n_{\mathrm{chamber}}\left(D_{\mathrm{geo}}\right) d D_{\mathrm{geo}}$

where $\Omega$ is the DMA fractional transmission at setpoint mobility diameter $D_{m}$ for geometric diameter $D_{\text {geo }}$ of a particle having charge $j$ (Knutson and Whitby, 1975). The term $\varphi$ is the fraction of particles of geometric diameter $D_{\text {geo }}$ having charge $j$ (Wiedensohler, 1988). The term $n_{\text {chamber }}\left(D_{\text {geo }}\right)$ is the particle size distribution irrespective of organic volume fraction (i.e., the distribution obtained by the SMPS) and is expressed as follows:

$n_{\text {chamber }}\left(D_{\text {geo }}\right)=\int_{0}^{1} n_{\text {chamber }}\left(\varepsilon_{\mathrm{ORG}} ; D_{\mathrm{geo}}\right) d \varepsilon_{\mathrm{ORG}}$.

The concentration $N_{\mathrm{CCNC}}\left(S ; D_{m}\right)$ of particles activated as $\mathrm{CCN}$ at supersaturation $S$ for the setpoint mobility diameter $D_{m}$ in Eq. (2) is calculated as follows:

$N_{\mathrm{CCNC}}\left(S ; D_{m}\right)=$

$\int_{0}^{1} \int_{0}^{\infty} \sum_{j=-\infty}^{+\infty} \Omega\left(D_{\mathrm{geo}}, j ; D_{m}\right) \varphi\left(D_{\mathrm{geo}}, j\right)$

$n_{\text {chamber }}\left(D_{\text {geo }}, \varepsilon_{\mathrm{ORG}}\right) \delta\left(D_{\mathrm{geo}}, \varepsilon_{\mathrm{ORG}} ; S\right) d D_{\mathrm{geo}} d \varepsilon_{\mathrm{ORG}}$,

where $\delta\left(D_{\text {geo }}, \varepsilon_{\mathrm{ORG}} ; S\right)$ takes a value of zero (not activated) for $S<S^{*}\left(D_{\mathrm{geo}}, \varepsilon_{\mathrm{ORG}}\right)$ or unity (activated) for $S \geq S^{*}\left(D_{\text {geo }}, \varepsilon_{\mathrm{ORG}}\right)$ and $S^{*}\left(D_{\mathrm{geo}}, \varepsilon_{\mathrm{ORG}}\right)$ is evaluated based on the maximum of Eq. (1).

Insight into $N_{\mathrm{CCNC}}\left(S ; D_{m}\right)$ and $F_{a}\left(S ; D_{m}\right)$ can be obtained by consideration of the cumulative distribution function of organic volume fraction $\operatorname{CDF}\left(\varepsilon_{\mathrm{ORG}} ; D_{m}\right)$ for a setpoint mobility diameter, which is calculated as follows: 

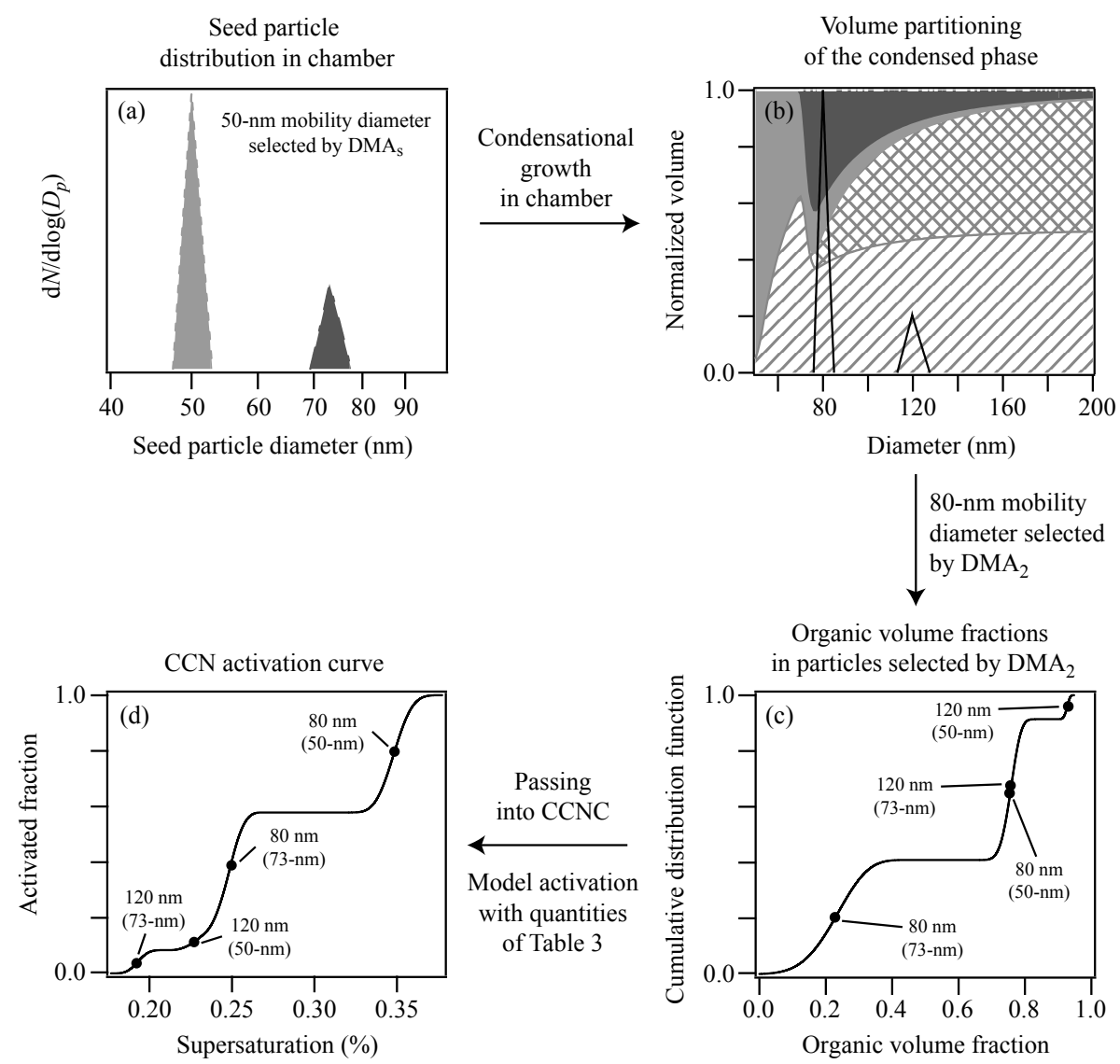

Fig. 3. Illustration of the experimental design and the model analysis. (a) Seed-particle geometric-size distribution for an electric-mobility diameter equivalent to 50-nm spherical particles having a +1 charge selected by $\mathrm{DMA}_{1}$. Light and dark gray represent singly and doubly charged particles, respectively. Although the actual model uses observed seed size distributions that have more highly charged particles and broader transmission functions, the illustration is simplified for presentation. (b) Volume partitioning for increasing geometric diameter between sulfate and organic particle-phase material: (light gray) the sulfate volume fraction arising from the 50-nm mode of seed particles, (dark gray) the sulfate volume fraction due to the 73-nm mode, (hashing) the volume fraction of organic material condensed onto the 50-nm seeds, and (crossed pattern) the volume fraction of organic material condensed onto the 73-nm seeds. Also shown are the geometricdiameter transmission windows of 80-nm mobility diameter for singly and doubly charged particles. The growth rate used in the illustration corresponds to the lowest loading of the experiments (i.e., $0.95 \mathrm{\mu g} \mathrm{m}^{-3}$ ). (c) Cumulative distribution function (CDF) of organic volume fraction for particles of 80-nm mobility diameter selected by $\mathrm{DMA}_{2}$. See main text for further description of the four particle compositions. (d) $\mathrm{CCN}$ activation curve for particles corresponding to panel $c$.

$\operatorname{CDF}\left(\varepsilon_{\mathrm{ORG}} ; D_{m}\right)=$

$N_{\mathrm{CPC}}^{-1}\left(D_{m}\right) \int_{0}^{\varepsilon_{\mathrm{ORG}}} \int_{0}^{\infty} \sum_{j=-\infty}^{+\infty} \Omega\left(D_{\mathrm{geo}}, j ; D_{m}\right)$

$\varphi\left(D_{\text {geo }}, j\right) n_{\text {chamber }}\left(D_{\text {geo }}, \varepsilon_{\mathrm{ORG}}^{\prime}\right) d D_{\text {geo }} d \varepsilon_{\mathrm{ORG}}^{\prime}$,

where $\varepsilon_{\mathrm{ORG}}^{\prime}$ is a dummy variable of integration. Comparison of Eqs. (2), (5), and (6) shows that $F_{a}\left(S ; D_{m}\right)$ corresponds to $\operatorname{CDF}\left(1 ; D_{m}\right)$ when a weighting factor $\delta\left(D_{\text {geo }}, \varepsilon_{\mathrm{ORG}} ; S\right)$ is added to the integration.

\subsection{Data analysis}

Figure 3 illustrates graphically the CCN activation curve embodied in the model of Eqs. (2), (5), and (7). Panel $a$ shows a cartoon of the geometric size distribution of seed particles selected by $\mathrm{DMA}_{1}$ for particles having an electric mobility equivalent to $50-\mathrm{nm}$ spherical particles of +1 charge. The panel shows modes at 50- and 73-nm geometric diameter, which correspond to singly and doubly charged particles. The width of the mode arises from the DMA transmission function, though for illustration purposes the example in Fig. 3 is overly narrow compared to the actual distribution used in the model. Low-volatility products from the dark ozonolysis of $\alpha$-pinene condense onto the seed particles of 
panel $a$, and the resulting volume partitioning among sulfate and organic material for increasing geometric diameter is illustrated in panel $b$. From the distribution shown in panel $b, 80-\mathrm{nm}(+1$ charge) and 120-nm (+2 charge) geometricdiameter modes are selected by setting $\mathrm{DMA}_{2}$ to an electric mobility equivalent to 80 -nm spherical particles of +1 charge. Overall heterogeneity in the particles withdrawn from the chamber then includes four types: (1) 80-nm mode grown on the 50-nm mode of the seed particles, (2) $80-\mathrm{nm}$ mode on 73-nm seeds, (3) 120-nm mode on 50-nm seeds, and (4) 120-nm mode on 73-nm seeds. These four types correspond to respective average organic volume fractions of 0.76 , $0.24,0.93$, and 0.77 . The resulting cumulative distribution function $(\mathrm{CDF})$ of particles withdrawn from the chamber is illustrated in panel $c$ (Eq. 7). The heterogeneity is further observed in the resulting CCN activation curve (Eq. 2) shown in panel $d$. The panel shows inflection points at the critical supersaturations corresponding to each particle type. The difference in critical supersaturation between $0.35 \%$ and $0.25 \%$ for the two organic volume fractions of 0.76 and 0.24 in the 80 -nm mode is greater than the corresponding difference in critical supersaturation between $0.225 \%$ and $0.19 \%$ for the organic volume fractions of 0.93 and 0.77 for the $120-\mathrm{nm}$ mode, emphasizing the importance of organic volume fraction on CCN activity.

For comparison to the approach embodied in Fig. 3, other treatments of multiply charged particles with $\mathrm{CCN}$ data analysis are presented in Rose et al. (2007) and Petters et al. (2007). Rose et al. subtract the activated fraction appearing as a plateau at lower supersaturations and corresponding to multiply charged particles (e.g., 120-nm mode on 73-nm seeds in panel $c$ of Fig. 3) to renormalize the activation curve. Petters et al. (2007) present an approach related to ours but differing in scanning of supersaturation rather than diameter. Our approach also extends that of Petters et al. (2007) by (1) incorporating variations of chemical composition in a forward Köhler model and (2) omitting a requirement of a definition of critical dry diameter or critical supersaturation from sigmoidal fits to observed data. Critical diameter or supersaturation is often defined as the diameter or supersaturation where $50 \%$ of the particles are $\mathrm{CCN}$ active (i.e., $F_{a}=0.5$ ), but this definition is frequently complicated by contributions from multiply charged particles (Petters et al., 2007). In the present study, this definition is also complicated by the chemical heterogeneity of the aerosol particles. Therefore, instead of finding a sigmoidal fit to the observed data, the observed $\mathrm{CCN}$ activation curves are modeled by the underlying physi$\mathrm{cal}$ and chemical properties of the particles.

\section{Results and discussion}

Typical size distributions of particles exiting the chamber are shown in Fig. 4. One distribution is shown for seed particles before injection of $\alpha$-pinene, and three distributions are shown for organic-sulfate particles at three steady-state conditions that differ by the amount of added $\alpha$-pinene. The latter distributions correspond to the lowest $\left(0.95 \mu \mathrm{g} \mathrm{m}^{-3}\right)$, midrange $\left(6.97 \mu \mathrm{g} \mathrm{m}^{-3}\right)$, and the highest $\left(\geq 95.2 \mu \mathrm{g} \mathrm{m}^{-3}\right)$ organic mass loadings of this study. As expected, particle diameter grows compared to the seed particles. The width of the distributions is also broader at higher loadings, representing the heterogeneity of particle residence times within the continuously stirred tank reactor.

Seinfeld et al. (2003) show that the size distribution $n_{\text {chamber }}\left(D_{\text {geo }}\right)$ at steady-state in a continuous-flow chamber satisfies the relation:

$$
\begin{aligned}
& \frac{d}{d D_{\text {geo }}}\left[I\left(D_{\text {geo }}\right) n_{\text {chamber }}\left(D_{\text {geo }}\right)\right]= \\
& -\left(\frac{1}{\tau}+\alpha\right) n_{\text {chamber }}\left(D_{\text {geo }}\right)+\frac{1}{\tau} n_{\text {seed }}\left(D_{\text {geo }}\right)
\end{aligned}
$$

where $\tau$ is the mean residence time in the chamber, $\alpha$ is the size-dependent wall-loss coefficient, $n_{\text {seed }}\left(D_{\text {geo }}\right)$ is the size distribution of the inflow seed particles, and $I\left(D_{\mathrm{geo}}\right)$ is the diameter-dependent growth rate of the particles. For our experiment, the only unknown is $I\left(D_{\text {geo }}\right)$. Least-squares optimization of Eq. (7) to the observed $n_{\text {chamber }}\left(D_{\text {geo }}\right)$ gives $I\left(D_{\text {geo }}\right)$. The results for $I\left(D_{\text {geo }}\right)$ at the three loadings of Fig. 4 are shown in Fig. 5. As expected, the growth rates at higher organic loadings are faster compared to those at lower loadings, and the growth rates decrease with increasing particle size. As a check on the optimization (i.e., accuracy of $\left.I\left(D_{\text {geo }}\right)\right)$, comparisons between the calculated $n_{\text {chamber }}\left(D_{\text {geo }}\right)$ based on $I\left(D_{\text {geo }}\right)$ and the measured $n_{\text {chamber }}\left(D_{\text {geo }}\right)$ are provided in the supplementary material and show good agreement.

When optimizing, we impose that the diameter-dependent growth rate $I\left(D_{\text {geo }}\right)$ must follow the form prescribed by Seinfeld et al. for a chemically nonreactive, semivolatile condensing species:

$$
I\left(D_{\mathrm{geo}}\right)=\sum_{i} \frac{\beta_{i}}{D_{\mathrm{geo}}+\lambda_{i}}
$$

where $i \in\{1,2\}$. Although Seinfeld et al. interpret these values mechanistically (i.e., as two effective condensing species of relative vapor pressures), we do not mean to make these specific implications for this study. We only state that this form of the growth equation (i.e., Eq. 8 with $i \in\{1,2\}$ ) has utility for formulating the growth-rate equation for use in modeling the steady-state size distribution (Eq. 7). Therefore, the possible covariances among $\beta_{i}$ and $\lambda_{i}$ are not considered in this study through a full sensitivity analysis for the optimization of Eq. (7).

From the aerosol exiting the chamber, particle modes of 80 - and $100-\mathrm{nm}$ equivalent diameter are selected using $\mathrm{DMA}_{2}$ for $\mathrm{CCN}$ analysis. The number distributions 


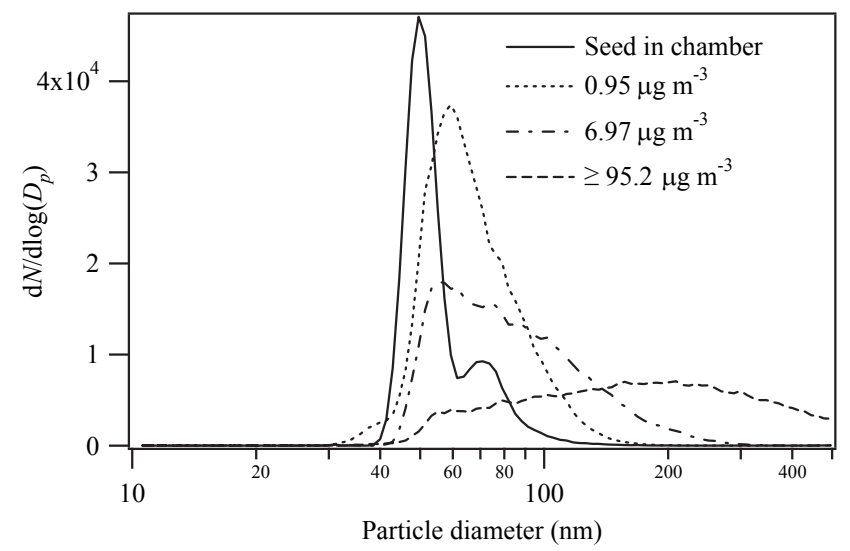

Fig. 4. Steady-state number size distributions measured by the SMPS. The solid line shows observations corresponding to the sulfate seed particles (i.e., no VOC injection) selected by $\mathrm{DMA}_{1}$ for an electric mobility diameter equivalent to 50 -nm spherical particles of +1 charge and then recharged in a neutralizer prior to entering the SMPS. The mode at $73 \mathrm{~nm}$ arises from particles doubly charged in DMA $_{1}$ but singly charged in the SMPS. The dashed lines show the size distributions after coating by organic material for three different mass loadings that represent the range of those used in this study. The SOA was prepared by the dark ozonolysis of $\alpha$-pinene at $25^{\circ} \mathrm{C}$ and $40 \%$ relative humidity.

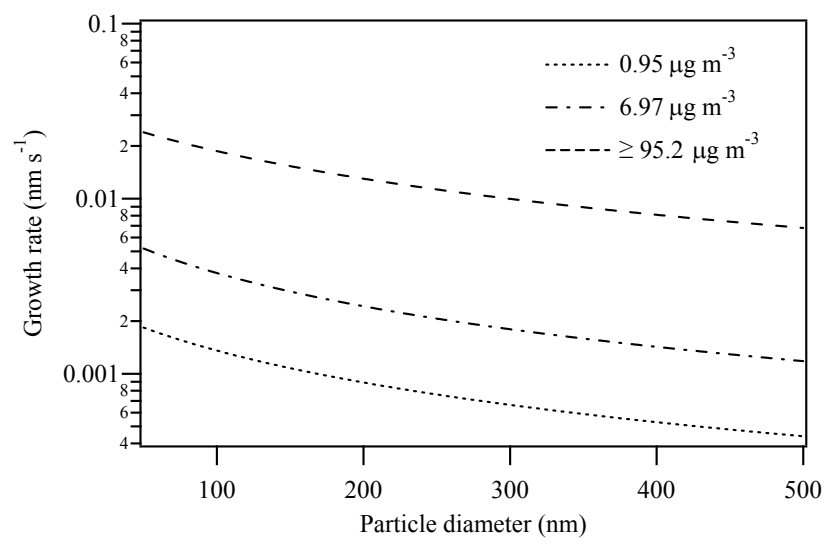

Fig. 5. Steady-state diameter-dependent growth rates for the three mass loadings shown in Fig. 4. These results are calculated from a best-fit model of the steady-state size distributions using the formulation of Seinfeld et al. (2003).

of organic volume fractions $n_{\text {chamber }}\left(D_{\mathrm{geo}}, \varepsilon_{\mathrm{ORG}} ; D_{m}\right)$ are modeled using the diameter-dependent growth rates and the observed seed particle size distribution. The resulting cumulative distribution functions $\operatorname{CDF}\left(\varepsilon_{\mathrm{ORG}} ; D_{m}\right)$ for a mobility-equivalent particle mode of $100 \mathrm{~nm}$ are shown in Fig. 6 for organic particle mass loadings of $0.95,6.97$, and $\geq 95.2 \mu \mathrm{g} \mathrm{m}{ }^{-3}$.

The observed and the modeled CCN activation curves are shown in Fig. 7. The modeled curves use Eq. (2) with the

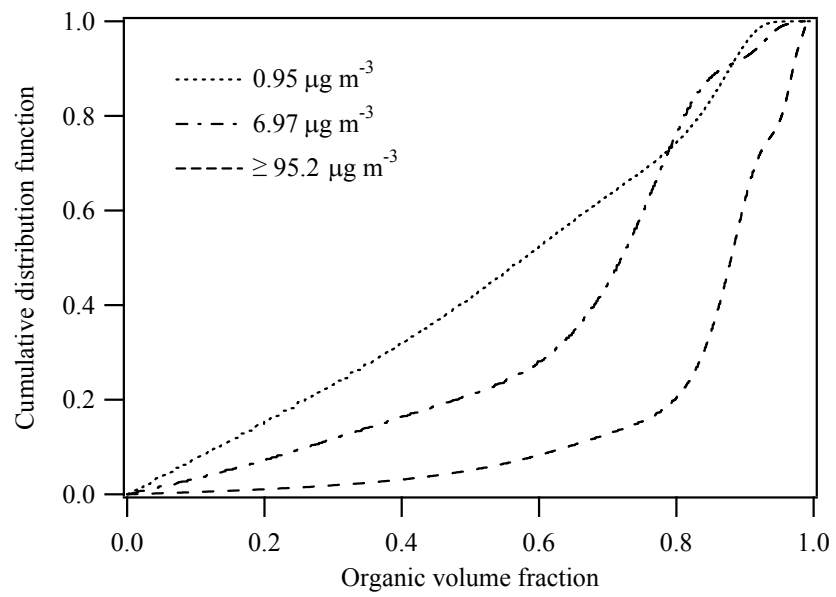

Fig. 6. Cumulative distribution functions of organic volume fraction $\varepsilon_{\mathrm{ORG}}$ for particles having an electric mobility diameter equivalent to $100-\mathrm{nm}$ spherical particles of +1 charge and selected by $\mathrm{DMA}_{2}$ from the three size distributions of Fig. 4. These curves are calculated using the best-fit growth rates of Fig. 5.

physicochemical Köhler parameters of Table 3 and incorporate $n_{\text {chamber }}\left(D_{\text {geo }}, \varepsilon_{\text {ORG }}\right)$ through Eq. (7). The shoulders at lower supersaturations arise from the contribution of multiply charged particles, especially for the higher loadings for which the selected mobility-equivalent diameter is on the ascending branch of the geometric size distribution (cf. Fig. 4, $\geq 95.2 \mu \mathrm{g} \mathrm{m}^{-3}$ ). In comparison, the shoulders for the lower loadings are small because of the reduced contribution by multiply charged particles when sampling the descending branch of the geometric size distribution.

Model calculations of mean $\varepsilon_{\mathrm{ORG}}$ demonstrate the necessity of considering the heterogeneity of the organic volume fraction for correct interpretation of the $\mathrm{CCN}$ activation curves. For example, the modeled mean $\varepsilon_{\mathrm{ORG}}$ for a mobility-equivalent particle mode of $100 \mathrm{~nm}$ at a loading of $\geq 95.2 \mu \mathrm{g} \mathrm{m}^{-3}$ is 0.840 . This value can be compared to 0.875 in a simpler calculation of organic volume fraction that assumes a homogenous seed particle geometric diameter of $50 \mathrm{~nm}$ for $100-\mathrm{nm}$ geometric diameter particles exiting the chamber. At a loading of $6.97 \mu \mathrm{g} \mathrm{m}^{-3}$, the mean $\varepsilon_{\mathrm{ORG}}$ shifts even further from 0.875 to 0.648 . For the lowest loading of $0.95 \mu \mathrm{g} \mathrm{m}^{-3}$, the modeled mean value is 0.546 . Model calculations of mean $\varepsilon_{\mathrm{ORG}}$ are also verified through agreement with independent measurements of organic volume fraction using HR-ToF-AMS observations of size-dependent sulfate and organic mass loadings (King et al., 2007).

Apparent in Fig. 7 from the trend in root mean squared errors (RMSE) is an increase in observed CCN activity compared to the model for particle mass loadings of $1.74 \mu \mathrm{g} \mathrm{m}^{-3}$ and less. The implication is that the physicochemical properties represented in Table 3 begin to change (e.g., a decrease in $V_{m, \text { ORG }}$ or in $\sigma$ ) for particle mass loadings of $1.74 \mu \mathrm{g} \mathrm{m}^{-3}$ and less. Mass spectral characterization of the particles 


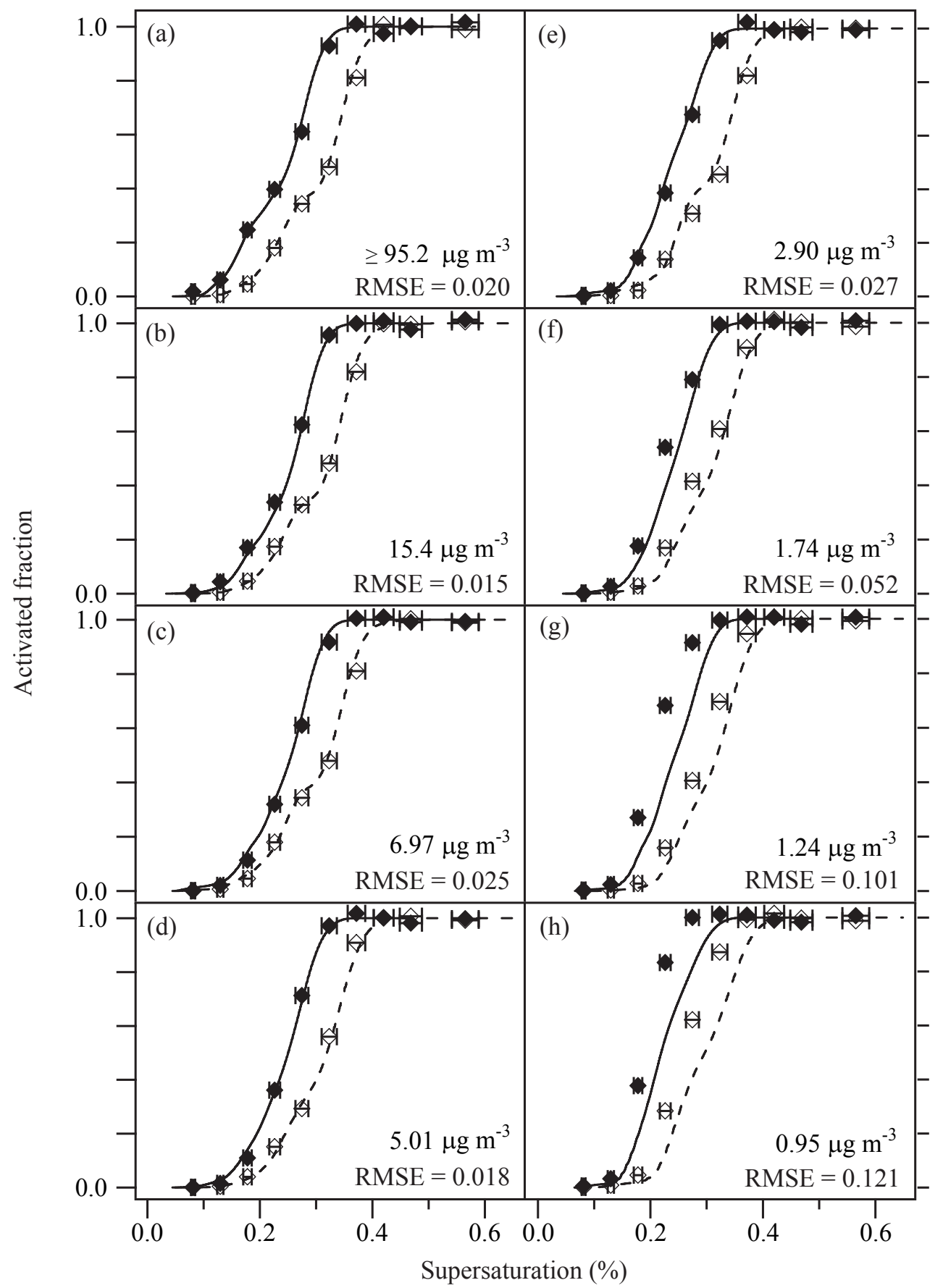

Fig. 7. Observed and modeled CCN activated fraction for increasing supersaturation. Observed data were collected for several hours and averaged. Panels show results from 0.95 to $\geq 95.2 \mu \mathrm{g} \mathrm{m}^{-3}$ organic particle mass loading. Solid symbols represent results for particles passing $\mathrm{DMA}_{2}$ when set to an equivalent electric-mobility diameter of $100 \mathrm{~nm}$ for spherical particles of +1 charge. Open symbols represent results for 80-nm electric-mobility-equivalent particles. The solid and dashed lines are the modeled CCN activation curves for these two mobility diameters (Fig. 3). Physical and chemical properties used in the model are provided in Table 3. The shown root mean squared errors (RMSE) are for the observations compared to models when summed for both particle sizes.

supports a change in chemical composition with lower loadings. For dark ozonolysis of $\alpha$-pinene, Grieshop et al. (2007) found that $m / z 44$ increased from $4 \%$ for $500 \mu \mathrm{g} \mathrm{m}^{-3}$, to $5 \%$ for $70 \mu \mathrm{g} \mathrm{m}^{-3}$, and to $7 \%$ for $10 \mu \mathrm{g} \mathrm{m}^{-3}$. In related studies in our chamber, we report in Shilling et al. (2009) that $m / z 44$ increases from $7 \%$ for $37 \mu_{g ~ m^{-3}}$, to $9 \%$ for $6 \mu \mathrm{g} \mathrm{m}^{-3}$, and to 


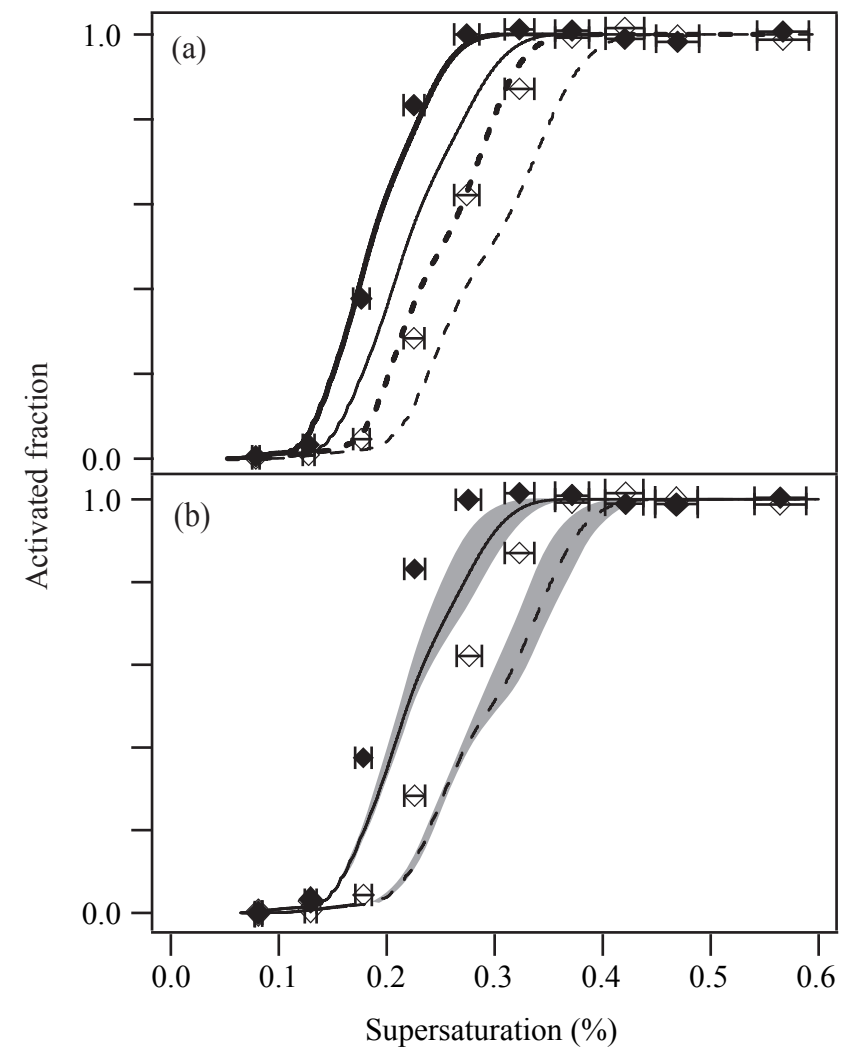

Fig. 8. Sensitivity of modeled activation curves at the lowest organic particle mass loading of $0.95 \mu \mathrm{g} \mathrm{m}^{-3}$ to (a) perturbation of $-10 \%$ in surface tension $\sigma$ and (b) perturbations of $\pm 25 \%$ in molar volume $V_{m, \text { ORG }}$ compared to the values given in Table 3. Legend: symbols and thin lines are as in Fig. 7. The bold lines in panel (a) represent the curves after perturbation of $-10 \%$ in $\sigma$. The gray region in panel (b) represents the results of perturbations of $\pm 25 \%$.

$11 \%$ for $0.5 \mu \mathrm{g} \mathrm{m}^{-3}$. Signal at $\mathrm{m} / \mathrm{z}, 44$ includes fragments of oxo- and di-carboxylic acids, and the increase for lower organic mass loadings plausibly indicates a corresponding increase in the mass fraction of these oxygenated, polar compounds, representing the types of organic molecules normally considered CCN active. Possible causes for the increase in oxygenated fraction at low loadings are discussed in Shilling et al. (2009). Notably, Capouet and Müller (2006) report that the volatility of carboxylic acids may be amongst the lowest of all the products of $\alpha$-pinene ozonolysis.

A perturbation analysis is performed to explore how isolated changes in $V_{m, \mathrm{ORG}}$ or $\sigma$ can improve the agreement between the observations and the model at the lowest studied mass loading $\left(0.95 \mu \mathrm{g} \mathrm{m}^{-3}\right)$. Figure 8 presents the results. An optimized fit of the CCN activation curves at 80- and 100$\mathrm{nm}$ equivalent mobility diameter is obtained when the surface tension is decreased by $10 \%$ to $0.065 \mathrm{~N} \mathrm{~m}^{-1}$ while maintaining $V_{m}$,ORG at $148 \mathrm{~cm}^{3} \mathrm{~mol}^{-1}$ (Fig. 8a). This decrease in surface tension is comparable to that reported by Engelhart et al. (2008), who inferred a decrease in surface tension from the $\mathrm{CCN}$ activity of particles prepared from aqueous resuspensions of filter samples of collected monoterpene SOA particle mass. The drop in particle surface tension occurs even as the organic volume fraction decreases with loading (Fig. 6). A decrease in surface tension might be explained by increased quantities of surface-active organic molecules at low loadings. These molecules would be associated with the organic species having lower volatilities that preferentially condense into the particle phase at low loadings, and their effects would be present even as the total relative organic volume fraction decreases at low loadings because of their surface partitioning. At high loadings, the effect of these molecules on surface tension would diminish because of the dilution accompanying the condensation of the highervolatility organic molecules.

As an alternative to changes in surface tension, shading in Fig. 8b shows how perturbations of $\pm 25 \%$ to $V_{m}$, ORG affect the modeled CCN activation curves. This perturbation corresponds to the maximum observed increase in $\rho_{\mathrm{ORG}}$, which is dependent upon loading lower than $15.9 \mu \mathrm{g} \mathrm{m}^{-3}$ and reaches its highest value in these experiments at a loading of $0.95 \mu \mathrm{g} \mathrm{m}^{-3}$ (Shilling et al., 2009). The smaller sensitivity to $V_{m}$, ORG for supersaturations less than $0.3 \%$ is explained by the larger contribution of ammonium sulfate (i.e., the organic fraction is small) at these supersaturations.

Combined changes in the physicochemical properties are also possible. For example, a $25 \%$ change in $V_{m}$,ORG combined with a $7 \%$ decrease in surface tension leads to agreement between observed and calculated activation. The sensitivity to another possibility, namely a $10 \%$ increase in the van't Hoff factor $i_{\mathrm{ORG}}$ at lower loadings (e.g., resulting from an increase in the relative fraction of carboxylic acids, which dissociate, or from nonidealities introduced by interactions between the organic and the inorganic components), is approximately equivalent to that of a $25 \%$ decrease in $V_{m}$, ORG (King et al., 2007). Combined changes within the particle can also be more complex than represented in our model. For example, the possible partitioning of more surface-active molecules from the droplet interior to the surface layer can change the droplet composition sufficiently to increase the water activity, thereby counteracting the effect of surface tension reduction (Sorjamaa et al., 2004; Prisle et al., 2008). This kind of possibility is not explicitly considered in our analysis.

As an alternative to the resolved-properties approach of Eq. (1), Petters and Kreidenweis introduced a lumped-sum parameter $\kappa$ (Petters and Kreidenweis, 2007). Agreement between the observed and modeled activation of Fig. 8 corresponds to an increase in $\kappa_{\mathrm{ORG}}$ to 0.16 at $0.95 \mu \mathrm{g} \mathrm{m}^{-3} \mathrm{com}-$ pared to 0.12 at higher mass loadings. For further comparison, Prenni et al. (2007) and Engelhart et al. (2008) obtained ranges of $\kappa$ values defined as $0.1 \pm 0.04$ and $0.15 \pm 0.08$, respectively, for several types of SOA particles produced by dark ozonolysis in the absence of seed particles in batch-mode experiments. Precursors in those studies 
included $\alpha$-pinene, $\beta$-pinene, limonene, and 3-carene. Additional variability in those studies may have occurred for any changes in $\mathrm{CCN}$ activity that tracked the time-dependent SOA particle mass loading during the course of batch-mode experiments. We observed $\kappa_{\mathrm{ORG}}$ to shift by 0.04 when SOA particle mass loading decreased, all other factors held constant, for the dark ozonolysis of $\alpha$-pinene.

In conclusion, the sensitivity analysis represented in Fig. 8 suggests that a drop in surface tension must be invoked to explain quantitatively the $\mathrm{CCN}$ observations at low SOA particle mass loadings. Other factors, such as decreased molecular weight, increased density, or increased van't Hoff factor, can contribute to the explanation but are quantitatively insufficient as the full explanation. As a hypothesis, an enrichment of carboxylic acids at low loadings, as suggested by Capouet and Müller (2006) and as consistent with the mass spectra reported by Shilling et al. (2009) for these experiments, anticipates a decrease in surface tension because carboxylic acids have been shown to reduce surface tension (Shulman et al., 1996; Hyvärinen et al., 2006; Topping et al., 2007; Tuckermann, 2007).

\section{Supplementary material available}

Equation (1) is derived in the supplementary material. Data shown in Fig. 7 are tabulated (Table S1). A comparison between the modeled and the observed steady-state size distributions is available (Fig. S1). See: http://www.atmos-chem-phys.net/9/2959/2009/ acp-9-2959-2009-supplement.pdf

Acknowledgements. This material is based upon work supported by the Office of Science (BES), US Department of Energy, Grant No. DE-FG02-08ER64529 and by the National Science Foundation under Grant No. ATM-0513463. Any opinions, findings, and conclusions or recommendations expressed in this material are those of the authors and do not necessarily reflect the views of the Department of Energy or the National Science Foundation. SMK acknowledges support from the EPA STAR fellowship program. TR acknowledges support from the Danish Agency for Science Technology and Innovation under Grant No. 272-06-0318. QC acknowledges support from the NASA Earth and Space Science Fellowship.

Edited by: R. Sander

\section{References}

Alofs, D. J. and Balakumar, P.: Inversion to obtain aerosol size distributions from measurements with a differential mobility analyzer, J. Aerosol Sci., 13, 513-527, 1982.

Capouet, M. and Müller, J. F.: A group contribution method for estimating the vapour pressures of $\alpha$-pinene oxidation products, Atmos. Chem. Phys., 6, 1455-1467, 2006, http://www.atmoschem-phys.net/6/1455/2006/.

Cocker, D. R., Clegg, S. L., Flagan, R. C., and Seinfeld, J. H.: The effect of water on gas-particle partitioning of secondary or- ganic aerosol. Part I: $\alpha$-pinene/ozone system, Atmos. Environ., 35, 6049-6072, 2001a.

Cocker, D. R., Flagan, R. C., and Seinfeld, J. H.: State-of-the-art chamber facility for studying atmospheric aerosol chemistry, Environ. Sci. Technol., 35, 2594-2601, 2001b.

Collins, D. R., Flagan, R. C., and Seinfeld, J. H.: Improved inversion of scanning DMA data, Aerosol Sci. Technol., 36, 1-9, 2002.

DeCarlo, P. F., Slowik, J. G., Worsnop, D. R., Davidovits, P., and Jimenez, J. L.: Particle morphology and density characterization by combined mobility and aerodynamic diameter measurements. Part 1: Theory, Aerosol Sci. Technol., 38, 1185-1205, 2004.

DeCarlo, P. F., Kimmel, J. R., Trimborn, A., Northway, M. J., Jayne, J. T., Aiken, A. C., Gonin, M., Fuhrer, K., Horvath, T., Docherty, K. S., Worsnop, D. R., and Jimenez, J. L.: Fielddeployable, high-resolution, time-of-flight aerosol mass spectrometer, Anal. Chem., 78, 8281-8289, 2006.

Donahue, N. M., Robinson, A. L., Stanier, C. O., and Pandis, S. N.: Coupled partitioning, dilution, and chemical aging of semivolatile organics, Environ. Sci. Technol., 40, 2635-2643, 2006.

Duplissy, J., Gysel, M., Alfarra, M. R., Dommen, J., Metzger, A., Prevot, A. S. H., Weingartner, E., Laaksonen, A., Raatikainen, T., Good, N., Turner, S. F., McFiggans, G., and Baltensperger, U.: Cloud forming potential of secondary organic aerosol under near atmospheric conditions, Geophys. Res. Lett., 35, L03818, doi:03810.01029/02007GL031075, 2008.

Engelhart, G. J., Asa-Awuku, A., Nenes, A., and Pandis, S. N.: CCN activity and droplet growth kinetics of fresh and aged monoterpene secondary organic aerosol, Atmos. Chem. Phys., 8, 39373949, 2008, http://www.atmos-chem-phys.net/8/3937/2008/.

Ervens, B., Feingold, G., and Kreidenweis, S. M.: Influence of water-soluble organic carbon on cloud drop number concentration, J. Geophys. Res., 110, D18211, doi:18210.11029/12004JD005634, 2005.

Facchini, M. C., Mircea, M., Fuzzi, S., and Charlson, R. J.: Cloud albedo enhancement by surface-active organic solutes in growing droplets, Nature, 401, 257-259, 1999.

Grieshop, A. P., Donahue, N. M., and Robinson, A. L.: Is the gas-particle partitioning in alpha-pinene secondary organic aerosol reversible?, Geophys. Res. Lett., 34, L14810, doi:14810.11029/12007GL029987, 2007.

Hartz, K. E. H., Rosenoern, T., Ferchak, S. R., Raymond, T. M., Bilde, M., Donahue, N. M., and Pandis, S. N.: Cloud condensation nuclei activation of monoterpene and sesquiterpene secondary organic aerosol, J. Geophys. Res., 110, D14208, doi:14210.11029/12004JD005754, 2005.

Hegg, D. A., Gao, S., Hoppel, W., Frick, G., Caffrey, P., Leaitch, W. R., Shantz, N., Ambrusko, J., and Albrechcinski, T.: Laboratory studies of the efficiency of selected organic aerosols as CCN, Atmos. Res., 58, 155-166, 2001.

Hyvärinen, A.-P., Lihavainen, H., Gaman, A., Vairila, L., Ojala, H., Kulmala, M., and Viisanen, Y.: Surface tensions and densities of oxalic, malonic, succinic, maleic, malic, and cis-pinonic acids, J. Chem. Eng. Data, 51, 255-260, 2006.

IPCC (Intergovernmental Panel on Climate Change): Climate Change 2007: The Physical Science Basis, Cambridge University Press, 2007.

Katrib, Y., Martin, S. T., Rudich, Y., Davidovits, P., Jayne, J. T., and 
Worsnop, D. R.: Density changes of aerosol particles as a result of chemical reaction, Atmos. Chem. Phys., 5, 275-291, 2005, http://www.atmos-chem-phys.net/5/275/2005/.

King, S. M., Rosenoern, T., Shilling, J. E., Chen, Q., and Martin, S. T.: Cloud condensation nucleus activity of secondary organic aerosol particles mixed with sulfate, Geophys. Res. Lett., 34, L24803, doi:24810.21029/22007GL030390, 2007.

Kleindienst, T. E., Smith, D. F., Li, W., Edney, E. O., Driscoll, D. J., Speer, R. E., and Weathers, W. S.: Secondary organic aerosol formation from the oxidation of aromatic hydrocarbons in the presence of dry submicron ammonium sulfate aerosol, Atmos. Environ., 33, 3669-3681, 1999.

Knutson, E. O. and Whitby, T. B.: Aerosol classification by electric mobility: Apparatus, theory, and applications, J. Aerosol Sci., 6, 443-451, 1975.

Kostenidou, E., Pathak, R. K., and Pandis, S. N.: An algorithm for the calculation of secondary organic aerosol density combining AMS and SMPS data, Aerosol Sci. Technol., 41, 1002-1010, 2007.

Lance, S., Medina, J., Smith, J. N., and Nenes, A.: Mapping the operation of the DMT Continuous Flow CCN counter, Aerosol Sci. Technol., 40, 242-254, 2006.

Lohmann, U. and Feichter, J.: Global indirect aerosol effects: a review, Atmos. Chem. Phys., 5, 715-737, 2005, http://www.atmoschem-phys.net/5/715/2005/.

McFiggans, G., Artaxo, P., Baltensperger, U., Coe, H., Facchini, M. C., Feingold, G., Fuzzi, S., Gysel, M., Laaksonen, A., Lohmann, U., Mentel, T. F., Murphy, D. M., O’Dowd, C. D., Snider, J. R., and Weingartner, E.: The effect of physical and chemical aerosol properties on warm cloud droplet activation, Atmos. Chem. Phys., 6, 2593-2649, 2006, http://www.atmoschem-phys.net/6/2593/2006/.

Paulsen, D., Dommen, J., Kalberer, M., Prevot, A. S. H., Richter, R., Sax, M., Steinbacher, M., Weingartner, E., and Baltensperger, U.: Secondary organic aerosol formation by irradiation of 1,3,5trimethylbenzene- $\mathrm{NO}_{\mathrm{x}}-\mathrm{H}_{2} \mathrm{O}$ in a new reaction chamber for atmospheric chemistry and physics, Environ. Sci. Technol., 39, 2668-2678, 2005.

Petters, M. D. and Kreidenweis, S. M.: A single parameter representation of hygroscopic growth and cloud condensation nucleus activity, Atmos. Chem. Phys., 7, 1961-1971, 2007, http://www.atmos-chem-phys.net/7/1961/2007/.

Petters, M. D., Prenni, A. J., Kreidenweis, S. M., and DeMott, P. J.: On measuring the critical diameter of cloud condensation nuclei using mobility selected aerosol, Aerosol Sci. Technol., 41, 907913, 2007.

Prenni, A. J., Petters, M. D., Kreidenweis, S. M., and DeMott, P. J.: Cloud droplet activation of secondary organic aerosol, J. Geophys. Res., 112, D10223, doi:10210.11029/12006JD007963, 2007.

Prisle, N. L., Raatikainen, T., Sorjamaa, R., Svenningsson, B., Laaksonen, A., Bilde, M.: Surfactant partitioning in cloud droplet activation: a study of C8, C10, C12 and C14 normal fatty acid sodium salts, Tellus, 60B, 416-431, 2008.

Roberts, G. C. and Nenes, A.: A continuous-flow streamwise thermal-gradient $\mathrm{CCN}$ chamber for atmospheric measurements, Aerosol Sci. Technol., 39, 206-221, 2005.

Rose, D., Frank, G. P., Dusek, U., Gunthe, S. S., Andreae, M. O., and Pöschl, U.: Calibration and measurement uncertainties of a continuous-flow cloud condensation nucleus counter (DMTCCNC): $\mathrm{CCN}$ activation of ammonium sulfate and sodium chloride aerosol particles in theory and experiment, Atmos. Chem. Phys., 8, 1153-1179, 2008, http://www.atmos-chemphys.net/8/1153/2008/.

Seinfeld, J. H., Kleindienst, T. E., Edney, E. O., and Cohen, J. B.: Aerosol growth in a steady-state, continuous flow chamber: Application to studies of secondary aerosol formation, Aerosol Sci. Technol., 37, 728-734, 2003.

Seinfeld, J. H. and Pankow, J. F.: Organic Atmospheric Particulate Material, Annu. Rev. Phys. Chem., 54, 121-140, 2003.

Shilling, J. E., King, S. M., Mochida, M., Worsnop, D. R., and Martin, S. T.: Mass spectral evidence that small changes in composition caused by oxidative aging processes alter aerosol CCN properties, J. Phys. Chem. A, 111, 3358-3368, 2007.

Shilling, J. E., Chen, Q., King, S. M., Rosenoern, T., Kroll, J. H., Worsnop, D. R., McKinney, K. A., and Martin, S. T.: Particle mass yield in secondary organic aerosol formed by the dark ozonolysis of $\alpha$-pinene, Atmos. Chem. Phys., 8, 2073-2088, 2008, http://www.atmos-chem-phys.net/8/2073/2008/.

Shilling, J. E., Chen, Q., King, S. M., Rosenoern, T., Kroll, J. H., Worsnop, D. R., DeCarlo, P. F., Aiken, A. C., Sueper, D., Jimenez, J. L., and Martin, S. T.: Loading-dependent elemental composition of $\alpha$-pinene SOA particles, Atmos. Chem. Phys. 9, 771-782,, 2009.

Shulman, M. L., Jacobson, M. C., Carlson, R. J., Synovec, R. E., and Young, T. E.: Dissolution behavior and surface tension effects of organic compounds in nucleating cloud droplets, Geophys. Res. Lett., 23, 277-280, 1996.

Sorjamaa, R., Svenningsson, B., Raatikainen, T., Henning, S., Bilde, M., Laaksonen, A.: The role of surfactants in Köhler theory reconsidered, Atmos. Chem. Phys., 4, 2107-2117, 2004, http://www.atmos-chem-phys.net/4/2107/2004/.

Stanier, C. O., Pathak, R. K., and Pandis, S. N.: Measurements of the volatility of aerosols from $\alpha$-pinene ozonolysis, Environ. Sci. Technol., 41, 2756-2763, 2007.

Svenningsson, B., Rissler, J., Swietlicki, E., Mircea, M., Bilde, M., Facchini, M. C., Decesari, S., Fuzzi, S., Zhou, J., Mønster, J., and Rosenoern, T.: Hygroscopic growth and critical supersaturations for mixed aerosol particles of inorganic and organic compounds of atmospheric relevance, Atmos. Chem. Phys., 6, 1937-1952, 2006, http://www.atmos-chem-phys.net/6/1937/2006/.

Topping, D. O., McFiggans, G. B., Kiss, G., Varga, Z., Facchini, M. C., Decesari, S., and Mircea, M.: Surface tensions of multi-component mixed inorganic/organic aqueous systems of atmospheric significance: measurements, model predictions and importance for cloud activation predictions, Atmos. Chem. Phys., 7, 2371-2398, 2007, http://www.atmos-chemphys.net/7/2371/2007/.

Tuckermann, R.: Surface tensions of aqueous solutions of watersoluble organic and inorganic compounds, Atmos. Env., 41, 6265-6275, 2007.

VanReken, T. M., Ng, N. L., Flagan, R. C., and Seinfeld, J. H.: Cloud condensation nucleus activation properties of biogenic secondary organic aerosol, J. Geophys. Res., 110, D07206, doi:07210.01029/02004JD005465, 2005.

Wiedensohler, A.: An approximation of the bipolar charge distribution for particles in the submicron size range, J. Aerosol Sci., 19, 387-389, 1988. 